\title{
BOND STRENGTH OF RESIN-RESIN INTERFACES CONTAMINATED WITH SALIVAAND SUBMITTED TO DIFFERENT SURFACE TREATMENTS
}

\author{
Adilson Yoshio FURUSE ${ }^{1}$, Leonardo Fernandes da CUNHA², Ana Raquel BENETTI ${ }^{1}$, José MONDELLI ${ }^{3}$
}

\author{
1- DDS, MSc, Department of Operative Dentistry, Endodontics, and Dental Materials, Bauru School of Dentisty, São Paulo State University, \\ Bauru, SP, Brazil. \\ 2- DDS, MSc, student, Department of Operative Dentistry, Endodontics, and Dental Materials, Bauru School of Dentisty, São Paulo State \\ University, Bauru, SP, Brazil. \\ 3- DDS, MSc, PhD, Department of Dentistry, Satate University of Maringá, Maringá, PR, Brazil. \\ 4- DDS, MSc, PhD, Department of Operative Dentistry, Endodontics, and Dental Materials, Bauru School of Dentisty, São Paulo State \\ University, Bauru, SP, Brazil. \\ Corresponding address: Adilson Yoshio Furuse - Departamento de Dentística, Endodontia e Materiais Dentários - Faculdade de Odontologia \\ de Bauru - Al. Octávio Pinheiro Brisolla, 9-75 - Vila Universitária, Bauru, SP, Brazil - 17012-901 - Phone: 55 (14) 3235-8365 / Fax: 55 (14) \\ 3235-8523 - e-mail: furuseay@yahoo.com.br
}

Received: August 2, 2007 - Modification: September 12, 2007 - Accepted: September 19, 2007

\begin{abstract}
$T_{\mathrm{h}}$

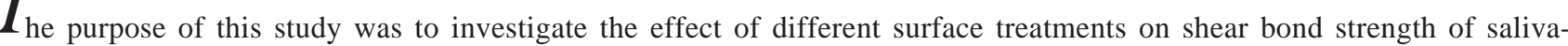
contaminated resin-resin interfaces. Flat resin surfaces were fabricated. In the control group, no contamination or surface treatment was performed. The resin surfaces of the experimental groups were contaminated with saliva and air-dried, and then submitted to: (G1) rinsing with water and drying; (G2) application of an adhesive system; (G3) rinsing and drying, abrasion with finishing disks, etching and application of adhesive system; (G4) rinsing and drying, etching, application of silane and adhesive system. Resin cylinders were placed over the treated surfaces. The specimens were stored in water or ethanol. Shear bond strength tests were performed and the mode of failure was evaluated. Data were submitted to two-way ANOVA and Dunnett T3 test. Contamination of resin-resin interfaces with saliva significantly reduced shear strength, especially after prolonged storage $(\mathrm{p}<0.05)$. Similar values to the original bond strength were obtained after abrasion and application of adhesive (G3) or etching and application of silane and adhesive (G4). If contamination occurs, a surface treatment is required to guarantee an adequate interaction between the resin increments.
\end{abstract}

Uniterms: Composite resins; Saliva; Contamination; Ethanol; Water

\section{INTRODUCTION}

The use of adhesive systems demands an operative field with controlled humidity and free of contamination of blood or saliva. Therefore, the use of rubber dam is always recommended.

Clinically, saliva contamination is a problem when new increments of composite are necessary to improve the contour of restorations after the rubber dam is removed. It may also be a problem when the use of rubber dam is not possible in time-consuming clinical procedures, especially in Pediatric Dentistry.

It is well documented that the contamination of enamel and dentin with saliva ${ }^{10,12,18,22,24}$ has resulted in lower bond strength between the composite resin and the tooth. However, information about the effect of contamination among increments of the composite resin ${ }^{8,9}$ and which decontamination method is needed to reestablish the original resin-resin bond strength is still required. Several studies have evaluated the resin-resin union between aged resin surfaces and new resin increments, simulating a repair condition. Different surface treatments have been proposed, with variable results. These methods include chemomechanical preparation of the resin surface, such as abrasion, etching with hydrofluoric or phosphoric acid and use of intermediate bonding agents to enhance repair bond strength ${ }^{4}$. While surface roughness promotes mechanical interlocking, the bonding agent improves surface wetting and chemical bonding with the new composite ${ }^{4}$. Abrasion of the aged resin surface with diamond burs ${ }^{2,3,19}$, carborundum $^{4}$, low-pressure silicate ceramic deposition ${ }^{3}$ or sandblasting ${ }^{2-5,19}$ provides satisfactory bond strength between the resin increments.

Additionally, the application of silane with or without 
previous mechanical preparation has been advised in composite resin repair. The use of silane has demonstrated controversial results ${ }^{2-4}$. In a study by Brosh, et al. ${ }^{4}$, silanization and unfilled resin slightly but not significantly improved the repair strength compared to unfilled resin alone. Silane application, in general, increased shear bond strength in surfaces with previous mechanical treatment, but it was material dependent in another study ${ }^{3}$ The use of silane combined with diamond bur roughening, on the other hand, significantly improved the bond strength between repaired surfaces ${ }^{2}$.

However, in case of contamination of recently inserted materials, the best approach to provide an appropriate union between the resin increments needs further investigation. Eiriksson, et al. ${ }^{9}$, recently reported a decrease in the microtensile bond strength at resin-resin interfaces contaminated with saliva. Additionally, it is interesting to evaluate the long-term behavior of the decontamination methods on the adhesive strength of the resin-resin interface. In vitro aging can be simulated in the laboratory by storage of specimens in aqueous solutions for prolonged periods ${ }^{7}$. The immersion in water at $37^{\circ} \mathrm{C}$ has been frequently used to simulate aging of the adhesive interface $\mathrm{e}^{6,7,15,16}$. On the other hand, the storage in ethanol solution may accelerate the degradation of the material by diffusion and softening of the resin ${ }^{1,17}$. A 75 vol\% ethanol aqueous solution simulates accelerated aging of restoration because it has a solubility parameter similar to that of the BisGMA and, therefore, results in maximum softening of the resin ${ }^{23}$. This solution can also be used as a food simulator in tests, ${ }^{11}$ which may be considered clinically relevant ${ }^{17}$.

Therefore, the purpose of this study was to evaluate the effect of saliva contamination on shear bond strength between resin-resin interfaces. A secondary goal was to compare the effect of decontamination methods on the shear bond strength after storage in water or ethanol. Working hypotheses were that saliva contamination modifies the shear bond strength of resin-resin interface and that different decontamination methods will reestablish the original bond strength.

\section{MATERIALAND METHODS}

All specimens were fabricated at controlled temperature ( $\left.23 \pm 1^{\circ} \mathrm{C}\right)$ and humidity (55 $\pm 5 \%$ ) conditions. One hundred and fifty specimens were manufactured by inserting increments of an Ormocer-based composite resin (Admira, color A2, VOCO GmbH, Germany) in a metallic matrix (diameter $5.5 \mathrm{~mm}$, height $3 \mathrm{~mm}$ ). The matrix was filled with two increments. A polyester strip and a glass lamina covered the final increment before polymerization, in order to achieve a flat surface. Each increment was light-activated continuously for 40 seconds at $500 \mathrm{~mW} / \mathrm{cm}^{2}$ (Elipar Trilight, 3M ESPE, Germany). Power density was monitored using the built-in radiometer of the light-curing unit.

The specimens were randomly allocated in five groups $(n=30)$. One group was assigned to be the control and it was not submitted to any contamination or surface treatment. Consequently, these specimens represented the cohesive strength of the material.

The four remaining experimental groups had the top surface of the composite resin contaminated with fresh human saliva. The saliva was collected from one person after stimulation with a piece of rubber. The saliva produced during the first minute was discarded and the saliva collected during the next minute was used for the fabrication of five specimens. This protocol was repeated until all specimens were fabricated. The saliva was then actively spread on the surface of the specimens for 10 seconds using a microbrush. Air drying was performed for 40 seconds at $45^{\circ}$ and a standard distance of $10 \mathrm{~cm}$, until a thin layer of dried saliva was visible. After water evaporation, only the solid components of the saliva were present on resin surface. Specimen preparation was immediately proceeded.

Four different treatments were tested directly on the contaminated surfaces:

- Group 1 (G1) - rinsing with water-spray for 20 seconds and oil-free air-drying for 40 seconds at a standard distance of $10 \mathrm{~cm}$;

- Group 2 (G2) - application of a single-component (primer/adhesive) adhesive system (Admira Bond Single Dose, VOCO GmbH, Germany) according to the manufacturer's instructions. After opening the adhesive blister, a microbrush was moistened with the product and the adhesive system was applied evenly on the surface for 30 seconds, air-thinned and light-cured for 20 seconds at $500 \mathrm{~mW} / \mathrm{cm}^{2}$ (Elipar Trilight);

- Group 3 (G3) - rinsing for 20 seconds and drying for 40 seconds. The resin surface was then abraded with finishing disks (Flexi disc, Coarse/Grey, Cosmedent, USA), rinsed (20 s), dried (40 s), etched with 35\% phosphoric acid (Vococid, VOCO) for 20 seconds, followed by rinsing (20s), drying (40s) and application of the adhesive system (Admira Bond Single Dose) according to the manufacturer's instructions;

- Group 4 (G4) - rinsing (20 s) and drying, etching (20 s), application of silane (Silano, Angelus, Brazil). The silane was spread on the resin surface using a microbrush, left undisturbed for 1 minute and gently air-dried Next, the adhesive system (Admira Bond Single Dose) was applied according to the manufacturer's instructions.

A split Teflon mold (diameter $3.6 \mathrm{~mm}$; height $2.5 \mathrm{~mm}$ ) was clamped to the treated resin surfaces and filled with the same composite resin (Admira, A2) in two increments. Each increment was light-cured continuously for 40 seconds at $500 \mathrm{~mW} / \mathrm{cm}^{2}$ (Elipar Trilight).

Specimens were then divided into three subgroups $(\mathrm{n}=$ 10) according to the storage conditions at $37^{\circ} \mathrm{C}$ in: distilled water for 24 hours; distilled water for 3 months; 75 vol\% ethanol solution for 3 months. Each specimen was immersed individually in a small bottle with cap. The solutions of the specimens stored for 3 months were replaced monthly to avoid saturation.

Shear bond strength was tested in a universal testing machine (EMIC, São José dos Pinhais, PR, Brazil). The wireloop method was adopted at crosshead speed of $0.5 \mathrm{~mm} /$ 
min. Means and standard deviation were calculated for each condition.

The failure modes were examined at 3x magnification under a precision magnifier (OptiVISOR $\AA$, Donegan Optical Company Inc., Kansas, USA). Failure was assessed as mainly adhesive or mainly cohesive in the composite resin. Failures were considered mainly adhesive if more than $80 \%$ of the fracture occurred at the interface, so a flat resin surface could be observed. Failures were considered mainly cohesive if more than $80 \%$ of the fracture occurred within the composite resin and an irregular surface was observed.

Data were submitted to two-way analysis of variance and Dunnett T3 test ( $\alpha=0.05$ ). Chi-square test was used to investigate the effect of the storage protocol and surface treatment on failure mode ( $\alpha=0.05)$. Pearson's correlation was used to verify the relationship between the number of adhesive failures and the shear bond strength $(\alpha=0.05)$.

\section{RESULTS}

Bond strength means (MPa) and standard deviations are presented in Table 1.

The analysis of variance detected significant differences for the surface treatments $(\mathrm{p}<0.001)$ and the storage condition $(p<0.001)$. An interaction effect was also found between the surface treatments and storage condition $(\mathrm{p}<0.001)$. As variances were not homogeneous, Dunnett T3 test was performed.

Regarding the surface treatments, the highest bond strength was registered for the control group, in which no surface treatment and no contamination with saliva were performed. The lowest bond strength $(\mathrm{p}<0.05)$ was observed when only rinsing and drying of the contaminated surface was performed (G1). The preparation of the contaminated resin surface and application of the adhesive system (G3) or etching and application of silane and adhesive (G4) resulted in similar values to the original bond strength (control group) for all storage conditions. The application of adhesive on the contaminated resin surface (G2) also resulted in similar values to those of the control group when it was stored in water for 24 hours or 3 months.

The effect of aging was relevant. The bond strength of all groups decreased as the storage period increased. Therefore, significantly lower bond strengths $(\mathrm{p}<0.05)$ were obtained after aging of the specimens for 3 months in water or ethanol. This result was also noticed for the control group, i.e. without saliva contamination, but no significant differences were found among the control group, G3 and G4, regardless of the storage condition. The effect of the storage on ethanol was particularly clear in G2, whose bond strength means decreased significantly compared to the control group ( $\mathrm{p}<0.05)$.

Regarding the failure modes, the number of specimens out of 10 that presented adhesive fractures for each surface

TABLE 1- Shear bond strength means (MPa) and standard deviation (SD) for each storage protocol and surface treatment. Values marked with an asterisk $\left(^{*}\right)$ are significantly different from the control $(p<0.05)$

\begin{tabular}{llll} 
& Water & Storage \\
& Water & Ethanol \\
& 24 hours & months & months \\
\hline Control & $37.3 \pm 5.0$ & $18.7 \pm 2.4$ & $16.7 \pm 3.9$ \\
G1 & $6.8 \pm 3.1 *$ & $4.1 \pm 2.9 *$ & $1.7 \pm 2.6 *$ \\
G2 & $27.2 \pm 10.1$ & $19.5 \pm 1.7$ & $1.3 \pm 2.1 *$ \\
G3 & $31.5 \pm 7.9$ & $19.3 \pm 1.6$ & $14.1 \pm 4.8$ \\
\hline
\end{tabular}

TABLE 2- Number of specimens out of 10 that showed mainly adhesive failure. Values marked with an asterisk $\left({ }^{\star}\right)$ are significantly different from the control group $(p<0.05)$

\begin{tabular}{lccc}
\hline & $\begin{array}{c}\text { Storage } \\
\text { Water } \\
24 \text { hours }\end{array}$ & $\begin{array}{c}\text { Ethanol } \\
\text { months }\end{array}$ & 3 months \\
\hline Control & 0 & 0 & 0 \\
G1 & $10 *$ & $10 *$ & $9 *$ \\
G2 & 2 & 0 & $10 *$ \\
G3 & 0 & 0 & 2 \\
G4 & 0 & 0 & 0
\end{tabular}


treatment is described in the Table 2. All the remaining failures that were not included in the table were considered mainly cohesive. For the Chi-square test, the values of all surface treatments were pooled to check for the effect of the storage protocol on the failure mode. The storage protocol did not influence the failure mode $(\mathrm{p}=0.06)$. Additionally, the values of all storage protocols were pooled to test for the effect of the surface treatments on the failure mode. Then, a significant effect of the surface treatment was observed on the failure mode ( $p<0.001)$. For all storage conditions, G1 resulted in significantly more adhesive failures when compared to the other surface treatments. A negative correlation was detected between the number of adhesive failures and the shear bond strength ( $\mathrm{p}<0.001)$.

\section{DISCUSSION}

Considering the results of this study, the working hypotheses should be accepted. Saliva contamination significantly reduces the adhesive strength between resin increments ${ }^{9}$. This probably occurrs due to the deposition of a film of glycoprotein sugars on the resin surface, even after water evaporation from saliva. In the present work, rinsing and drying of the contaminated surface only (G1) were not enough to reestablish adequate bond strength. It is possible that, once saliva contacts the composite resin, a salivary pellicle deposits on the surface, thus lowering its bond strength with the next layer, even if the saliva is rinsed with water ${ }^{9}$. Therefore, a surface treatment is recommended to improve the interaction between resin increments.

The application of adhesive on the recently contaminated surface has demonstrated good results ${ }^{9}$. Similar findings were obtained in the present study (G2) when specimens were stored in distilled water during 24 hours or 3 months. Brosh, et al. ${ }^{4}$ also observed that the application of adhesive, alone or combined with silane, was the most effective procedure for enhancing the shear bond strength of the repaired composite specimens. The use of bonding agents allows a better surface wetting and infiltration of the resin. Additionally, single-bottle adhesives, such as the one used in this study, contain solvents that seem able to denature the glycoprotein sugars and remove the saliva contamination ${ }^{9}$.

Etching of the contaminated surface followed by application of silane and adhesive (G4) also resulted in similar bond strength values to the control group. Brosh, et al. ${ }^{4}$ suggested that silane might be unnecessary in the repair of composite resins because the combination of silane and adhesive did not significantly improve the repair strength when compared with adhesive alone. On the contrary, silane application significantly affected bond strength in the study carried out by Bouschlicher, et al. ${ }^{3}$. In that case, the increase in shear bond strengths after silane application was a general trend, but different results were observed for the different composite resins tested. Additionally, these authors tested the use of silane combined to different mechanical preparations of the resin surface, such as diamond bur, sandblasting with aluminum oxide or tribomechanical silica deposition.

The mechanical preparation of the contaminated surface and application of the adhesive system (G3), on the other hand, provided satisfactory bond strength between the resin increments. This finding is in accordance with those of previous studies, which reported adequate shear bond strength between the resin increments after abrasion of the resin surface ${ }^{2-5,19}$. Apparently, mechanical interlocking is the most significant factor contributing to repair strength.

Although some studies have investigated the effect of contamination and decontamination between resin increments, none of them evaluated the long-term effect of the different surface treatments. Thus, the storage protocols in this study were chosen to simulate the effect of aging in the shear bond strength.

Storage in water is frequently used as an in vitro aging medium. When considering adhesion of resin to the dentin, a decrease in the adhesive strength has been found after aging in water ${ }^{15,20}$. A significant decrease was observed in the shear bond strength in the groups stored for three months. It is believed that the water sorption causes resin softening by swelling of the polymer network and decreasing of the frictional forces between the polymeric chains ${ }^{14}$.

Ethanol may also be used as an aging medium ${ }^{1,17,23}$. After penetrating in the polymer network, ethanol causes an expansion of the structure, allowing the release of uncured monomers and causing dissolution of linear polymer chains ${ }^{13}$. Therefore, storage in ethanol influenced the results of this study. In general, lower shear bond strengths can be noticed for all groups after storage in ethanol. A particular effect of ethanol was noticed in G2. Although the application of adhesive on the recently contaminated surface (G2) resulted in bond strengths similar to the control groups when specimens were stored in distilled water, a significant decrease in shear bond strength was observed for such treatment after storage in ethanol. It seems that possible remaining components of the saliva compromised the adhesive penetration in the micro-retentive areas on the resin surface, thus favoring the solubility of the adhesive in ethanol. These results suggest that the application of an adhesive over the contaminated resin surface may have a poor long-term stability.

Considering the storage for 3 months in distilled water or ethanol, no significant differences were observed in the shear bond strength between the control groups, abrasion of the resin surface and application of adhesive (G3) or etching and application of silane and adhesive (G4). This confirms the high stability of these surface treatments when compared to the other treatments tested.

Regarding the failure mode, lower bond strengths were significantly correlated with mainly adhesive fractures. Bouschlicher, et al. ${ }^{3}$ also observed that lower shear bond strengths of repaired composite demonstrated failure patterns that were primarily adhesive. Likewise, TruffierBoutry, et al. ${ }^{21}$ detected predominantly adhesive failures after saliva contamination. The predominantly flat surfaces detected during the failure mode analysis suggest that if 
the saliva pellicle deposited at the resin surface is not properly removed, a poor interaction between the resin increments will occur. It must be mentioned, however, that each material has individual characteristics and, consequently, may behave differently. Therefore, the results of the present work should not be extrapolated to all composite resins and adhesive systems.

\section{CONCLUSION}

If contamination with saliva occurs during the insertion of composite resin, an effective decontamination of the surface must be performed to improve the adhesive strength between resin-resin increments. Briefly, either the abrasion of the contaminated surface followed by application of the adhesive system, or the application of silane and adhesive, resulted in more stable resin-resin bonding.

\section{ACKNOWLEDGEMENTS}

Authors acknowledge the grant from PIBIC/CNPq (Programa Institucional de Bolsas de Iniciação Científica do Conselho Nacional de Desenvolvimento Científico e Tecnológico, Brasil) and the donation of the materials used in this study by the respective manufacturers.

\section{REFERENCES}

1- Asmussen E. Softening of BISGMA-based polymers by ethanol and by organic acids of plaque. Scand J Dent Res. 1984;92:257-61.

2- Bonstein T, Garlapo D, Donarummo J Jr., Bush PJ. Evaluation of varied repair protocols applied to aged composite resin. J Adhes Dent. 2005;7:41-9.

3- Bouschlicher MR, Reinhardt JW, Vargas MA. Surface treatment techniques for resin composite repair. Am J Dent. 1997;10:279-83.

4- Brosh T, Pilo R, Bichacho N, Blutstein R. Effect of combinations of surface treatments and bonding agents on the bond strength of repaired composites. J Prosthet Dent. 1997;77:122-6.

5- Cavalcanti AN, De Lima AF, Peris AR, Mitsui FH, Marchi GM. Effect of surface treatments and bonding agents on the bond strength of repaired composites. J Esthet Restor Dent. 2007;19:90-8; discussion 99

6- Chiba Y, Yamaguchi K, Miyazaki M, Tsubota K, Takamizawa T, Moore BK. Effect of air-drying time of single-application self-etch adhesives on dentin bond strength. Oper Dent. 2006;31:233-9.

7- De Munck J, Van Landuyt K, Peumans M, Poitevin A, Lambrechts $\mathrm{P}$, Braem M, et al. A critical review of the durability of adhesion to tooth tissue: methods and results. J Dent Res. 2005;84:118-32.

8- Eiriksson SO, Pereira PN, Swift EJ, Heymann HO, Sigurdsson A. Effects of blood contamination on resin-resin bond strength. Dent Mater. 2004;20:184-90.

9- Eiriksson SO, Pereira PN, Swift EJ Jr., Heymann HO, Sigurdsson A. Effects of saliva contamination on resin-resin bond strength. Dent Mater. 2004;20:37-44
10- el-Kalla IH, Garcia-Godoy F. Saliva contamination and bond strength of single-bottle adhesives to enamel and dentin. Am J Dent. 1997;10:83-7.

11- FDA. Guidelines for Chemistry and technology requirements of indirect additive petitions. Food and Drug Administration;Washington, DC.; 1976

12- Feigal RJ, Musherure P, Gillespie B, Levy-Polack M, Quelhas I, Hebling J. Improved sealant retention with bonding agents: a clinical study of two-bottle and single-bottle systems. J Dent Res. 2000;79:1850-6.

13- Ferracane JL. Elution of leachable components from composites. J Oral Rehabil. 1994;21:441-52.

14- Ferracane JL, Berge HX, Condon JR. In vitro aging of dental composites in water-effect of degree of conversion, filler volume, and filler/matrix coupling. J Biomed Mater Res. 1998;42:465-72.

15- Giannini M, Seixas CA, Reis AF, Pimenta LA. Six-month storagetime evaluation of one-bottle adhesive systems to dentin. J Esthet Restor Dent. 2003;15:43-8; discussion 49.

16- Hashimoto K, Inai N, Tagami J. Evaluation of the light intensity of high intensity light units. Am J Dent. 2006;19:143-6.

17- Lee SY, Huang HM, Lin CY, Shih YH. Leached components from dental composites in oral simulating fluids and the resultant composite strengths. J Oral Rehabil. 1998;25:575-88.

18- Nemeth BR, Wiltshire WA, Lavelle CL. Shear/peel bond strength of orthodontic attachments to moist and dry enamel. Am J Orthod Dentofacial Orthop. 2006;129:396-401.

19- Papacchini F, Dall’Oca S, Chieffi N, Goracci C, Sadek FT, Suh BI et al. Composite-to-composite microtensile bond strength in the repair of a microfilled hybrid resin: effect of surface treatment and oxygen inhibition. J Adhes Dent. 2007;9:25-31.

20- Shono Y, Terashita M, Shimada J, Kozono Y, Carvalho RM, Russell CM et al. Durability of resin-dentin bonds. J Adhes Dent. 1999;1:211-8.

21- Truffier-Boutry D, Place E, Devaux J, Leloup G. Interfacial layer characterization in dental composite. J Oral Rehabil. 2003;30:74-7.

22- van Schalkwyk JH, Botha FS, van der Vyver PJ, de Wet FA, Botha SJ. Effect of biological contamination on dentine bond strength of adhesive resins. Sadj. 2003;58:143-7.

23- Wu W, McKinney JE. Influence of chemicals on wear of dental composites. J Dent Res. 1982;61:1180-3.

24- Yoo HM, Oh TS, Pereira PN. Effect of saliva contamination on the microshear bond strength of one-step self-etching adhesive systems to dentin. Oper Dent. 2006;31:127-34. 